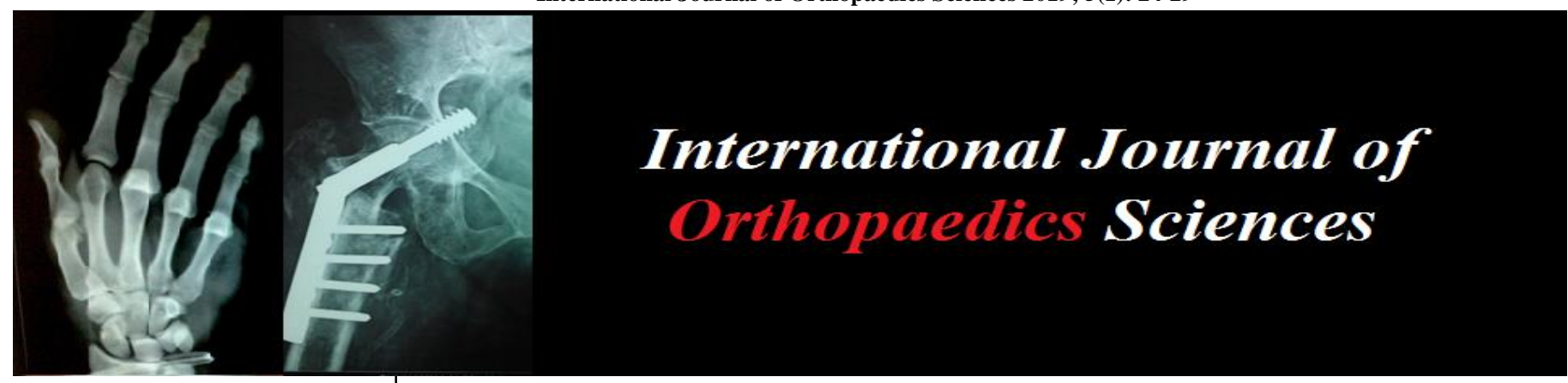

ISSN: $2395-1958$

IJOS 2019; 5(1): 24-29

(C) 2019 IJOS

www.orthopaper.com

Received: 11-11-2018

Accepted: 15-12-2018

Dr. Mayur B Vania

Senior Resident, GMERS medical college, Junagadh, Gujarat, India

\section{A retrospective analysis of extra articular glenoid neck fracture of scapula (A study of 20 cases)}

\author{
Dr. Mayur B Vania
}

DOI: https://doi.org/10.22271/ortho.2019.v5.i1a.05

\section{Abstract}

Introduction: Since long ago the scapula fracture is treated conservatively and most of time it works because scapula is a flat bone and coated with bulky muscle. So, nonunion of the fracture is usually not a problem, and most of time, due to very high arc of motion of shoulder joint, even in malunited fractures, mild to moderate restriction of the range of motion not create significant problem. But the actual problem comes when fracture through the glenoid neck or glenoid fossa cause derangement in the biomechanics of shoulder joint, or associated fracture of clavicle - 'The floating shoulder' cause significant instability of shoulder joint. Recent advances and proper understanding of the biomechanics of the shoulder joints open a new chapter of operative management for better quality of life.

In this study we retrospectively tried to understand that which fractures can be treated conservatively and which one require fixation.

Aim: To study retrospectively extraarticular glenoid neck fractures of scapula (a study of 20 cases).

Materials and Methods: Total 20 patients having extra articular scapular neck fracture, with following criteria are included in this study. All patients were treated by consultant orthopedic surgeons of the department of orthopedics of Guru Gobindsingh Hospital, Jamnagar only. All patients are evaluated retrospectively. Patients having fracture of appendicles (Fracture of acromion, coracoid and spine), body as well as intra articular glenoid fracture were not included in this study. So this study was concerned only with stable and unstable scapular neck fracture. All patients are evaluated with Herscovici shoulder scoring system to make this study comparable with other study universally.

Results: Our study shows excellent results in 16 out of 20 scapular fractures as well as 4 good results, according to Herscovici shoulder scoring system. Most common complication is subacromial pain especially at night while sleeping on that side. Incidence of mild exertional pain is $45 \%$ while loss of useful abduction was $10 \%$ and superficial infection is $5 \%$.

Conclusion: To conclude, this rare type of fracture has high incidence of significant associated injury. Among all scapular fractures extra articular displaced glenoid fracture and floating shoulder type injury should get special attention regards of its treatment, because closed observation and intelligence can make vast change in its outcome.

Keywords: extra articular, glenoid, scapula, neck fracture

\section{Introduction}

Scapula fractures account for $<1 \%$ of all fractures, $3 \%$ of shoulder girdle injuries and $5 \%$ of all shoulder fractures. Out of scapular fractures, approximately $50 \%$ involve the body and spine, fractures of the glenoid neck constitute about $20 \%-25 \%$, fractures of the glenoid cavity (glenoid rim and fossa) make up approximately $10 \%$ of scapula fractures, the acromial processes account for $8 \%$ of it, the coracoid processes about $7 \%$, floating shoulder accounts for $<0.1 \%$. Modes of injury for Glenoid neck Fracture include direct trauma to shoulder, fall on outstretched hand or fall on the point of shoulder, association with clavicle fracture (Floating shoulder).

It is worthless to say that all life threating conditions which are usually associated with scapular fractures should attain first and promptly and then accordingly to patient's general condition, age, functional demand etc., should take into consideration before choosing the final modality of treatment. Since long ago the scapula fracture is treated conservatively and most of time it works because scapula is a flat bone and coated with bulky muscle. So, nonunion of the fracture is usually not a problem, and most of time, 
due to very high arc of motion of shoulder joint, even in malunited fractures, mild to moderate restriction of the range of motion not create significant problem. But the actual problem comes when fracture through the glenoid neck or glenoid fossa cause derangement in the biomechanics of shoulder joint, or associated fracture of clavicle - 'The floating shoulder' cause significant instability of shoulder joint. Recent advances and proper understanding of the biomechanics of the shoulder joints open a new chapter of operative management for better quality of life.

In this study we retrospectively tried to understand that which fractures can be treated conservatively and which one require fixation.

AIM: To study retrospectively extraarticular glenoid neck fractures of scapula (a study of 20 cases).

\section{Materials and Methods}

Total 20 patients having extra articular scapular neck fracture, with following criteria are included in this study. All patients were treated by consultant orthopedic surgeons of the department of orthopedics of Guru Gobindsingh Hospital, Jamnagar only. All of them sustained injury between the periods of September 2002 to September 2007. All patients are evaluated retrospectively. Patients having fracture of appendicles (Fracture of acromion, coracoid and spine), body as well as intra articular glenoid fracture were not included in this study. So this study was concerned only with stable and unstable scapular neck fracture.

\section{Methods for evaluation}

All patients were counseled personally on their one of the follow up visit and evaluate with help of a detailed proforma. Investigations: Pre-operative X-rays were carried out and studies for the classification and sub-classification of scapular injury, to study associated injury, Glenopolar and inclination angle and measurement of displacement. For Follow up Investigation, plain x-rays were carried to determine status of fracture union, signs of infection, signs of arthritis, signs of humeral head subluxation. X-rays were carried out in Standard anteroposterior view, Scapula ' $Y$ ' view, Axial view. Ultrasonography was carried out to rule out rotator cuff tear. Postoperative X-rays were carried out to study the implant placement and to calculate the Post-operative correction of glenopolar and inclination angle.

\section{Follow Up examination}

Patients were examined for Range of movements like Abduction, External rotation / Internal rotation, Flexion/ extension. (All movement were checked both actively and passively), Power of muscles and complaints. Patients were also examined for the presence and severity of pain, treatment of pain and discharging sinus/pus, if any. Following examination, patients were advised for lifestyle modification, and for any residual deformity due to associated injury.

All patients are evaluated with Herscovici shoulder scoring system to make this study comparable with other study universally.

\section{Observation}

The 20 patients with scapular facture, who were treated in Guru Gobindsingh Hospital, Jamnagar between period of September 2002 to September 2007 were evaluated retrospectively as followed.
Table 1: Age Distribution

\begin{tabular}{|c|c|c|}
\hline Age range & No. of patients & Percentage \\
\hline$\leq 15$ yrs. & 00 & $00 \%$ \\
\hline 16 to 25 yrs. & 01 & $05 \%$ \\
\hline 26 to 35 yrs. & 08 & $40 \%$ \\
\hline 36 to 45 yrs. & 01 & $05 \%$ \\
\hline 46 to 55 yrs. & 06 & $30 \%$ \\
\hline$\geq 56$ yrs. & 04 & $20 \%$ \\
\hline Total & 20 & $100 \%$ \\
\hline
\end{tabular}

This mode of distribution shows bimodal incidence of scapular fracture.

1. 26 to 35 years, the younger group for who these are most active years of life.

2. $\geq 46$ years, the older people who can't sustain minor trauma.

Table 2: Sex Distribution

\begin{tabular}{|c|c|c|}
\hline Sex & No. of patients & Percentage \\
\hline Male & 15 & $75 \%$ \\
\hline Female & 05 & $25 \%$ \\
\hline Total & 20 & $100 \%$ \\
\hline
\end{tabular}

This shows Male: Female ration 3:1.

Table 3: Laterality

\begin{tabular}{|c|c|c|}
\hline Side involved & No. of patients & Percentage \\
\hline Unilateral & 19 & $95 \%$ \\
\hline Bilateral & 01 & $05 \%$ \\
\hline Total & 20 & $100 \%$ \\
\hline
\end{tabular}

Most of the patient having unilateral injury.

Table 4: Side Involved

\begin{tabular}{|c|c|c|}
\hline Side involved & No. of scapula & Percentage \\
\hline Right & 13 & $61.9 \%$ \\
\hline Left & 08 & $38.1 \%$ \\
\hline Total & 21 & $100 \%$ \\
\hline
\end{tabular}

Right side involvement is more that left one.

Table 5: Occupational Relation

\begin{tabular}{|c|c|c|}
\hline Type of occupation & No. of patients & Percentage \\
\hline Farmer & 06 & $30 \%$ \\
\hline Labor & 06 & $30 \%$ \\
\hline Sedentary jobs & 05 & $25 \%$ \\
\hline Household works & 03 & $15 \%$ \\
\hline Total & 20 & $100 \%$ \\
\hline
\end{tabular}

Heavy workers are usually more prone to get injury.

Table 6: The Mode of Injury

\begin{tabular}{|c|c|c|}
\hline Type of injury & No. of patients & Percentage \\
\hline Direct blow to shoulder & 09 & $45 \%$ \\
\hline Indirect injury & 11 & $55 \%$ \\
\hline Total & 20 & $100 \%$ \\
\hline
\end{tabular}

Table 7: Classification

\begin{tabular}{|c|c|c|}
\hline $\begin{array}{c}\text { Type (According to anatomical } \\
\text { classification) }\end{array}$ & $\begin{array}{c}\text { No. of } \\
\text { scapula }\end{array}$ & Percentage \\
\hline EA I & 09 & $42.9 \%$ \\
\hline EA II & 12 & $57.1 \%$ \\
\hline Total & 21 & $100 \%$ \\
\hline
\end{tabular}

$(\mathrm{EA}=$ Extra articular glenoid neck fracture) 
Most of fractures are associated with clavicle fracture, though all of them should not consider as unstable fracture pattern.

Table 8: Classification (Ada and Miller)

\begin{tabular}{|c|c|c|}
\hline $\begin{array}{c}\text { Type (According to Ada and } \\
\text { Miller) }\end{array}$ & $\begin{array}{c}\text { No. of } \\
\text { scapula }\end{array}$ & Percentage \\
\hline Type II A & 02 & $09.6 \%$ \\
\hline Type II B & 14 & $66.6 \%$ \\
\hline Type II C & 05 & $23.8 \%$ \\
\hline Total & 21 & $100 \%$ \\
\hline
\end{tabular}

Type II B constitutes about $2 / 3^{\text {rd }}$ of total glenoid neck fractures.

Table 9: Co-Relation between Mode of Injury And It's Classifiction

\begin{tabular}{|c|c|c|c|}
\hline Classification & Direct injury & Indirect injury & Total \\
\hline EA I & 07 & 02 & 09 \\
\hline EA II & 02 & 10 & 12 \\
\hline Total & 09 & 12 & 21 \\
\hline
\end{tabular}

(Here patient no. 15 counts twice in indirect injury as he has bilateral injury, on Right side type II and left side type I injury.)
Bold numbers shows that direct injury more commonly cause only scapular fracture, while indirect one cause both clavicle and scapula.

Table 10: The Glenopolar Angle (In Degrees)

\begin{tabular}{|c|c|c|}
\hline Glenopolar angle $\mathbf{(}^{\circ}$ ) & No. of scapula & Percentage \\
\hline $11-20$ & 05 & $23.8 \%$ \\
\hline $21-30$ & 11 & $52.4 \%$ \\
\hline $31-40$ & 05 & $23.8 \%$ \\
\hline Total & 21 & $100 \%$ \\
\hline
\end{tabular}

Most fracture cause moderate amount of displacement in glenopolar angle, which cause much confusion in treatment plan making.

Table 11: Co-Relation between Glenopolar Angle and Classification (1)

\begin{tabular}{|c|c|c|c|}
\hline Glenopolar angle $^{\left({ }^{\circ}\right.}$ ) & EA I & EA II & Total \\
\hline $11-25$ & 03 & 07 & 10 \\
\hline $26-40$ & 06 & 05 & 11 \\
\hline Total & 09 & 12 & 21 \\
\hline
\end{tabular}

Most scapular fractures, when associated with clavicle fracture more prone to disturb glenopolar angle.

Table 12: Co-Relation between Glenopolar Angle and Classification (2)

\begin{tabular}{|c|c|c|c|c|}
\hline Glenopolar angle $\mathbf{(}^{\circ}$ ) & Type II A & Type II B & Type II C & Total \\
\hline $11-25$ & 00 & 06 & 02 & 08 \\
\hline $26-40$ & 02 & 08 & 03 & 13 \\
\hline Total & 02 & 14 & 05 & 21 \\
\hline
\end{tabular}

Table 13: Incidence of Associtaed Injuries

\begin{tabular}{|c|c|c|}
\hline Associated injury & No. of Patients & Percentage \\
\hline Rib fracture (multiple) & 03 & $15 \%$ \\
\hline Clavicle fracture & 11 & $55 \%$ \\
\hline Head injury & 03 & $15 \%$ \\
\hline Respiratory track injury & 00 & $00 \%$ \\
\hline Blunt abdominal injury & 00 & $00 \%$ \\
\hline Spinal injury & 02 & $10 \%$ \\
\hline Long bone Fracture & 02 & $10 \%$ \\
\hline Neurovascular injury & 00 & $00 \%$ \\
\hline Death & 01 & $05 \%$ \\
\hline None & 05 & $25 \%$ \\
\hline
\end{tabular}

Multiple rib fractures and clavicle fracture are more commonly associated with extra articular scapular neck fractures.
Table 14: Modality of Treatment

\begin{tabular}{|c|c|c|}
\hline Method & No. of scapula & Percentage \\
\hline Operative & 09 & $42.9 \%$ \\
\hline Conservative & 12 & $57.1 \%$ \\
\hline Total & 21 & $100 \%$ \\
\hline
\end{tabular}

Conservative management still good in most of scapular neck fracture specially when not associated with clavicle fracture.

Table 15: Incidence of One or Both Sturt Fixation

\begin{tabular}{|c|c|c|}
\hline Method & No. of fixation & Percentage \\
\hline Scapula alone & 04 & $44.4 \%$ \\
\hline Clavicle alone & 02 & $22.2 \%$ \\
\hline Both & 03 & $33.4 \%$ \\
\hline Total & 09 & $100 \%$ \\
\hline
\end{tabular}

Table 16: Duration of Immobilization \& Relation to Classification

\begin{tabular}{|c|c|c|c|c|}
\hline Duration (Approximately in wks) & EA I & EA II & No of shoulder & Percentage \\
\hline$\leq 1 \mathrm{wk}$. & $00(0 \%)$ & $02(100 \%)$ & 02 & $10 \%$ \\
\hline$\leq 2 \mathrm{wks}$. & $05(41.7 \%)$ & $07(58.3 \%)$ & 12 & $60 \%$ \\
\hline$\leq 3 \mathrm{wks}$. & $02(33.3 \%)$ & $04(66.7 \%)$ & 06 & $30 \%$ \\
\hline Total & $07(35 \%)$ & $13(65 \%)$ & 20 & $100 \%$ \\
\hline
\end{tabular}

(Here the patient who died not included but the patient having bilateral fracture count as 2 shoulder so total no of shoulder remain 20) Most of the fracture can be mobilized between 1 to 2 weeks of injury.

Table 17: Duration of return occupational activity

\begin{tabular}{|c|c|c|}
\hline Duration after injury (Approximately) & No. of patient & Percentage \\
\hline$\leq 6 \mathrm{wks}$ & 03 & $15.8 \%$ \\
\hline$\leq 8 \mathrm{wks}$ & 05 & $26.3 \%$ \\
\hline$\leq 10 \mathrm{wks}$ & 06 & $31.5 \%$ \\
\hline$>10 \mathrm{wks}$ & 03 & $15.8 \%$ \\
\hline Can't & 02 & $10.6 \%$ \\
\hline Total & 19 & $100 \%$ \\
\hline
\end{tabular}


Most of patients can return to their normal activity within $8 \mathrm{t}$ 10 weeks of injury.

Table 18: Duration of Follow up (In Months)

\begin{tabular}{|c|c|}
\hline Duration (Approximately) & No. of patients \\
\hline$\leq 2$ months & 03 \\
\hline 2 to $\leq 4$ months & 05 \\
\hline 4 to $\leq 6$ months & 02 \\
\hline 6 to $\leq 8$ months & 01 \\
\hline 8 to $\leq 10$ months & 03 \\
\hline$>10$ months & 05 \\
\hline Average follow up & $6.2 \%$ \\
\hline
\end{tabular}

The average is some what misguiding here. If we exclude the extreme value, the average follow up in this study is around 3 months.

Table 19: Functional outcome according to herscovici shoulder scoring system

\begin{tabular}{|c|c|c|}
\hline Results & No. of shoulder & Percentage \\
\hline Excellent & 16 & $80 \%$ \\
\hline Good & 04 & $20 \%$ \\
\hline Fair & 00 & - \\
\hline Poor & 00 & - \\
\hline Total & 20 & $100 \%$ \\
\hline
\end{tabular}

Most of patients are satisfied with results.

Table 20: Relation between Result and Modality of Treatment

\begin{tabular}{|c|c|c|c|}
\hline Result & Operative & Conservative & Total \\
\hline Excellent & 05 & 11 & 16 \\
\hline Good & 04 & 00 & 04 \\
\hline Fair & 00 & 00 & 00 \\
\hline Poor & 00 & 00 & 00 \\
\hline Total & 09 & 11 & 20 \\
\hline
\end{tabular}

Though the table suggest result are better with conservative treatment it is not like that, because the candidate selected for operative management having unstable fracture pattern.

Table 21: Comparision between Result and Type of Injury

\begin{tabular}{|c|c|c|c|}
\hline Results & EA I & EA II & Total \\
\hline Excellent & $09(100 \%)$ & $07(63.6 \%)$ & 16 \\
\hline Good & 00 & $04(36.4 \%)$ & 04 \\
\hline Fair & 00 & 00 & 00 \\
\hline Poor & 00 & 00 & 00 \\
\hline Total & 09 & 11 & 20 \\
\hline
\end{tabular}

All four good results are in type 2 suggest that most of scapular fracture when alone are stable and give good results.

\section{Discussion}

In this study we retrospectively tried to evaluate the significance of scapular neck fracture and effect of various factors, which influence on its final outcome. Discussion about various facts of 20 patients treated in Guru Gobindsingh hospital, Jamnagar, between September 2002 to September 2007 isas follows.

Age: Age distribution in our study shows bimodal age incidences with range between $24-70$ years and mean age about 43 years. Range of age distribution in Herscovici et al. study was 17 to 58 yrs. (29.6 yrs.), in David \& Timothy et al. $15-83$ yrs. (33 yrs.), in Leung et al. $18-41$ yrs. (31 yrs.), in Hardegger et al. 17 to 85 yrs. (42 yrs.), and in Ada and Miller et al. 5 - 75 yrs. (25.3 yrs.). All above clearly state that this rare injury is more common in young active life followed by in old age.

Young active life is at high risk due to involvement in heavy work and traveling. In this age group the severity of trauma is more and usually associated with the some associated injury, which may be fatal. The indirect mechanism of causing scapular fracture is more commonly seen in this age group. This is because the young bones are tough as well as ligaments and bulky muscles surrounding it, which are as tough as bone, by means of indirect force (usually fall on outstretched hand) cause fracture of linked bone. In older age group fall directly on shoulder usually cause scapular fracture. Osteoporosis and poor soft tissue support make bone easy to break. These injuries are usually less severe in nature.

Sex: Males are more prone to get this injury, as reflected in our study male female ratio is 3:1. In Leung et al. affected male were $100 \%$, while in David \& Timothy et al they were $80.4 \%$. Males are more prone to get this injury, more probably due to involvement in outdoor activity, traveling, and heavy work. Severe injuries are also more common in man.

Laterality: Bilateral incidence in our study is $5 \%$, while that of $2.7 \%$ in Ada \& Miller et al. These injuries are usually severe and incidence of associated injuries are more with it.

Side of Injury: - In present series right side $(61.9 \%)$ somewhat more prone to get injured might be because of being a dominant hand and its involvement in various activities and in protective reflex. In leung et al. its occurance was $60 \%$, while in Ada \& Miller et al. and David \& Timothy et al. it was $50 \%$. But in Herscovici incidence for right side was $33 \%$ only.

Mode of injury: Most common cause of mode of injury is road traffic accidents (80\%) followed by fall on affected side and assaulted injury. The accidents as a cause of injury were $61 \%$ in Ada \& Miller et al., 70\% in David and Trimothy et al., $47 \%$ in Leung et al.

Open v/s closed injury: In our study all injuries are closed, 1 patient having compound grade I injury over clavicle. In Ada \& Miller et al. $7 \%$ injuries are open caused by gunshot wound mostly, while in Herscovici et al. all injuries were closed.

Occupation: $60 \%$ patients of our series are involved in heavy work and outdoor activity. Those who have sedentary type of work got injured usually in road side accidents.

Classification: In our study $57.1 \%$ fractures are of extraarticular type II glenoid neck fracture. While in Leung et al. its incidence was $57.7 \%$ and in David \& Timothy et al. it was $47.4 \%$.

Associated injuries: In our study association of other injuries to extra articular glenoid neck fracture in descending order is as follows: clavicle fractures, rib fractures, head injury, spinal injury, and femur fractures. Outcome of these associated injuries usually uneventful.

In other studies it was as follows: Leung et al.: Clavicle fracture, Head injury, rib fractures, pulmonary contusions and femur fractures. David and Trimothy et al.: Pulmonary contusions, rib fractures, clavicle fractures, brachial plexus injury, vascular injury. 
Death of one patient in our study is due to thoracic spinal injury which reflects severity of this injury. This also reflects that scapula fracture is not a cause of direct mortality.

Stability: Most of glenoid neck fractures are unstable (57\%) and usually associated with indirect mechanism of injury. This usually having low $(52.4 \%)$ glenopolar angle $\left(<25^{\circ}\right)$ and require surgical fixation $(67 \%)$. In our study, most of patients having glenopolar angle between $20^{\circ}$ to $30^{\circ}$ create significant confusion in management plan because patients also have satisfactory result when treating conservatively. Glenopolar angle $<20^{\circ}$, inclination angle more than $40^{\circ}$ and $>5 \mathrm{~mm}$ of displacement usually associated with poor outcome unless treated surgically to correct it in acceptable position. Glenopolar angle disturbed more when osseoligamentous disruption in shoulder suspensory complex occurs.

Surgical management: Surgical management is good in unstable fractures when glenopolar angle is less than $20^{\circ}$ and displacement less than $5 \mathrm{~mm}$. In our study incidence of fixation of either strut is $67 \%$ while, that of both is $33 \%$.

Review of literature says that in case of associated ipsilateral clavicular fracture it is better to operate first for clavicular oseteosysnthesis alone, because technically fixation of clavicle is easy operation that restore normal contour of the shoulder. By pulling the soft tissues out to length, surgical intervention neutralizes the deforming gravitational and muscular forces. This procedure should be followed by per operative check for scapular neck alignment and displacement under image intensifier, and even if one found that the superior shoulder suspensory complex is still unstable, it is wise to go for scapular fixation also. The aim should be to maintain proper glenopolar angle. But, according to our study fixation of both struts would be better management.

Conservative management: In our study $57.1 \%$ patients treated conservatively and all has excellent result, though most of them have stable variety and having low energy trauma.

Average follow-up: Average follow up in our study is 6.2 months. Average follow up in Herscovici et al. was 48.5 months, in Leung et al. 25 months, in Van noor et al. 35 months, Hashiguchi et al. 57.4 months, and in Edward et al. 28 months.

Duration of recovery: According to our study the usual period of immobilization is $10-12$ days and between 8 to 10 weeks' patients usually get near full range of movement if every thing was going right. In Leung et al. the average duration to get full range of movement was 6 to 9 weeks. It is better to mobilize patients as early as pain reduced to prevent stiffness. Started with pendulum exercise followed by abduction-adduction, flexion-extension and rotatory exercise till full range of movement achieved.

Results: Our study shows excellent results in 16 out of 20 scapular fractures as well as 4 good results, according to Herscovici shoulder scoring system. Among the four patients one having rotator cuff tear which was not repaired at time of surgery and patient having limitation in abduction. Second one was not willing for operation at time of injury and 2 month late clavicular fixation only was done. Remaining 2 were involved in heavy labor work and pain on exertion make them unsatisfied. In Hersocivici et al. out of 9 patients 7 patients were treated surgically and all had excellent results. While out of 2 treated conservatively 1 had good and 1 had poor result. In Ramos et al. out of 13 patients treated surgically 11 had excellent result while 1 had good and 1 had poor result. In Edwards, et al. out of 20 patients treated surgically 17 patients had excellent and 3 patients had good results. Overall results of extra-articular glenoid neck fractures are usually excellent if treated properly.

Complications: Most common complication is subacromial pain especially at night while sleeping on that side. Incidence of mild exertional pain is $45 \%$ while loss of useful abduction was $10 \%$ and superficial infection is $5 \%$.

\section{Conclusion}

To conclude, this rare type of fracture has high incidence of significant associated injury. Among all scapular fractures extra articular displaced glenoid fracture and floating shoulder type injury should get special attention regards of its treatment, because closed observation and intelligence can make vast change in its outcome. Management of this entity is controversial but most accepted theory is to determine stability by means of fracture patterns (GPA $\leq 20^{\circ}$, inclination angle $>40^{\circ}$, clavicular displacement $>10 \mathrm{~mm}$ ) and according plan can be made. Among operative methods fixation of both struts is better modality of management particularly in a case of floating shoulder. Though if contraindicated clavicular fixation may sometimes serve the purpose. The aim should be proper maintenance of glenopolar and inclination angles. Results are excellent when treated properly, especially when fracture pattern is of stable type. Complication is mild exert tonal pain in subacromial space is common one, followed by limited abduction and internal rotation.

\section{References}

1. Goss T: Scapular fractures and dislocation: Diagnosis and treatment. J Am Acad Orthop Surg. 1995; 3:22-33.

2. Fractures in adults. by Roockwood and Green's, sixth ediion, 2:1257-84.

3. Gray's Anatomy. The anatomical basis of medicine and surgery; Thirty eight edition.

4. Surgical exposure in orthopaedics, The anatomic approach; by Stanley Hoppenfeld \& Piet deBoer: Third edition.

5. Wilber MC, Evans EB. Fractures of scapula; analysis of forty cases and a review of literature; JBJS, 1977, 358-62.

6. Jon Mclennan G. Pneumothorax complicating fracture of the scapula; JBJS, 1982, 598-599.

7. Jesse Ada R, Michael Miller E. Scapular fracture analyasis of 113 cases; Corr. 1991; 269:174-180.

8. David Thompson A, Timothy Flynn C. The significance of scapular fractures. The Journal of Trauma. 25(10):974977.

9. Leung KS. Open reduction and internal fixation of ipsilateral fractures of the scapular neck and clavicle; JBJS. 1993; 75-A(7):1015-18.

10. Herscovici et al. The floating shoulder: ipsilateral clavicle and scapular neck fractures. JBJS. 1992; 74B(3):362-64.

11. Brian Kavangh E. Open reduction and internal fixation of displaced intra articular fractures of glenoid fossa. 1993; 75-A(4):479-84.

12. Shoulder Lesions, By Moseley HF. second edition.

13. Michael DeFranco J, Brendan Patterson M. The Floating Shoulder; American academy of orthopeadic surgeons. 
2006; 14(8):499-509.

14. Rikli D, Regazzoni P, Renner N. The unstable shoulder girdle: Early functional treatment utilizing open reduction and internal fixation. Journal Orthop Trauma. 1995; 9:9397.

15. Herscovici Jr D, Sanders R, DiPasquale T, Gregory P. Injuries of the shoulder girdle. CORR. 1995; 318:54-60.

16. Hashiguchi H, Ito H. Clinical outcome of the treatment of floating shoulder by osteosynthesis for clavicle fracture alone. Journal of shoulder and elbow surgery. 2003; 12:589-91.

17. Edwards SG, Whittle AP, Wood GWII. Nonoperative treatment of ipsilateral fractures of the scapula and clavicle. JBJS American. 2000; 82:774-80.

18. Williams GR Jr, Narania J, Klimkiewicz J, Karduna A, Lannotti JP, Ramsey M. The floating shoulder: A biomechanical basis for classification and management. JBJS American. 2001; 83:1182-87.

19. Hardegger FH, Simpson LA, Weber BG. The operative treatment of scapular fractures. JBJS British. 1984; 66:725-31.

20. Ramos L, Mencia R, Alonso A, Ferrandez L. Conservative treatment of ipsilateral fractures of the scapula and clavicle. Jouranl Trauma. 1997; 42:239-242.

21. Campbell's Operative orthopaedics; Tenth edition, 3.

22. Egol KA, Connor PM, Karunakar MA, Sims SH, Bosse MJ, Kellam JF. The floating shoulder: Clinical and functional results. J Bone Joint Surg Am. 2001; 83:11881194.

23. Goss TP. Fractures of the glenoid neck, I shoulder Elbow Surg. 1994; 3:42-52.

24. Van Noort A, Te Slaa RL, Marti RK, Van der Werken C. The floating shoulder: A multicentre study: J Bone Joint Surg Br. 2001, 83:795-798.

25. Labler L, Platz A, Weishaupt D, Trentz O. Clinical and functional results after floating shoulder injuries. J Trauma. 2004; 57:595-602.

26. Mc Adams TR, Blevins FT, Martin TP, DeCoster TA. The role of plain films and computed tomography in the evaluation of scapular neck fractures, J Orthop Trauma. 2002; 16:7-11.

27. Edwards SG, Wood GWIII, Whittle AP. Factors associated with short form-36 outcomes in nonoperative treatment for ipsilateral fractures of the clavicle and scapula. Orthopedics. 2002; 25:733-738.

28. Merrill's Atlas of Radiography position \& Radiologic procedures. Philip W Ballinger, 6th Edi. 